\title{
Application of a lipid-coated hollow calcium phosphate nanoparticle in synergistic co-delivery of doxorubicin and paclitaxel for the treatment of human lung cancer A549 cells
}

\author{
This article was published in the following Dove Press journal: \\ International Journal of Nanomedicine \\ 31 October 2017 \\ Number of times this article has been viewed
}

\section{Chao Wu \\ Jie $\mathrm{Xu}$ \\ Yanna Hao \\ Ying Zhao \\ Yang Qiu \\ Jie Jiang \\ Tong Yu \\ Peng Ji \\ Ying Liu}

Pharmacy School, Jinzhou Medical University, Jinzhou, China
Correspondence: jie $\mathrm{Xu}$

Pharmacy School, Jinzhou Medical University, 40 Songpo Road, Linghe, Jinzhou, Liaoning 121000 , China

Tel +864164673439

Email xu9086I3808@I63.com

\begin{abstract}
In this study, we developed a lipid-coated hollow calcium phosphate (LCP) nanoparticle for the combined application of two chemotherapeutic drugs to human lung cancer A549 cells. Hydrophilic doxorubicin (DOX) was incorporated into the hollow structure of hollow calcium phosphate (HCP), and a lipid bilayer containing hydrophobic paclitaxel (PTX) was subsequently coated on the surface of HCP. The study on combinational effects demonstrated that the combination of DOX and PTX at a mass ratio of 12:1 showed a synergistic effect against A549 cells. The particle size, zeta potential, and encapsulation efficiency were measured to obtain optimal values: particle size was $335.03 .2 \mathrm{~nm}$, zeta potential $-41.1 \mathrm{mV}$, and encapsulation efficiency $80.40 \% \pm 2.24 \%$. An in vitro release study indicated that LCP produced a sustained drug release. A549 cells had a better uptake of LCP with good biocompatibility. Furthermore, in vitro cytotoxicity experiment, apoptosis analysis, in vivo anti-tumor efficacy and protein expression analysis of Bax, Bcl-2, and Caspase-3 demonstrated that the co-delivery system based on LCP had significant synergistic anti-tumor activity. All conclusions suggested that LCP is a promising platform for co-delivery of multiple anti-tumor drugs.

Keywords: doxorubicin, paclitaxel, co-delivery, lipid, hollow calcium phosphate, lung cancer cell
\end{abstract}

\section{Introduction}

Lung cancer has become the leading cause of cancer deaths due to smoking and air pollution in recent years. Chemotherapy and radiation therapy are main methods of cancer treatment. Treatment with single chemotherapeutic drugs has shown many limitations, such as undesirable side effects, drug resistance, biotoxicity, and low bioavailability. ${ }^{1}$ To overcome these defects, a synergistic co-delivery drug system has been developed that attracted considerable attention. Drug combinations not only reduce the frequency and dosage of drug administration but also relieve drug resistance and improve therapeutic efficacy. ${ }^{2,3}$

The combination of doxorubicin (DOX) and paclitaxel (PTX) is the most effective and common regimen in first-line lung tumor treatments. ${ }^{4}$ It is worth noting that DOX and PTX possess different water solubility and action mechanisms. DOX, as a hydrophilic drug, binds to DNA or RNA to inhibit synthesis of nucleic acids, while PTX, as a hydrophobic drug, acts on tubulin and inhibits cell mitosis. ${ }^{5}$ Chen et al successfully designed and developed pluronic-based functional polymeric mixed micelles for the co-delivery of DOX and PTX to multidrug-resistant human breast cancer tumors. ${ }^{6}$ 
Feng et al prepared porous poly lactic-co-glycolic acid (PLGA) microspheres for synergistic co-delivery of DOX and PTX in pulmonary inhalation treatments. ${ }^{7}$ Wang et al enhanced the anti-tumor efficacy by co-delivery of DOX and PTX with amphiphilic methoxy PEG-PLGA copolymer nanoparticles on three different types of tumor cells. ${ }^{8}$ However, these synergistic co-delivery drug systems have low drug loading, and the two drugs with a synergistic effect are generally disproportioned with one having a larger proportion than the other. According to the literature, when the molar ratio of DOX to PTX is greater than 1:1, the combination of drugs has a synergistic effect, and the effect increases with increases in the DOX/PTX ratio. ${ }^{7}$ In the clinical setting, it is easy to overlook the water solubility, optimal dose ratio of synergistic co-delivery, drug loading capacity, and interaction for these carriers. Therefore, it is meaningful to develop a new drug-delivery system with optimal parameters for the delivery of drug combinations.

Nanoparticles with hollow structures provide a good structure base. Nanometer hollow structures have larger volumes, which are suitable for drug storage, and the shell structures can increase drug diffusion resistance and regulate drug release. ${ }^{9-11}$ For poorly water-soluble drugs, the space limited effect of hollow nanostructures can inhibit drug crystallinity, decrease drug particle size, and improve drug water solubility. At present, there are many studies on the application of hollow nanoparticles to improve the water solubility of insoluble drugs and regulate drug release. ${ }^{12}$ For inorganic hollow nanoparticles, undegradability and toxicity are inevitable issues. Problems with organic hollow nanoparticles include shrinking and collapsing during the preparation process and poor dispersibility. ${ }^{13}$

Calcium phosphate $\left(\mathrm{Ca}_{3}\left(\mathrm{PO}_{4}\right)_{2}\right)$, a biocompatible inorganic material, possesses stable physicochemical properties, bioactivity, and $\mathrm{pH}$ sensitivity. ${ }^{14}$ This makes $\mathrm{Ca}_{3}\left(\mathrm{PO}_{4}\right)_{2}$ a potential platform for synergistic co-delivery system. In this study, we designed a biocompatible phospholipid-coated drug-delivery system based on hollow calcium phosphate (HCP) nanoparticles for co-delivery of DOX and PTX to enhance the anti-tumor efficacy of drugs on human lung cancer A549 cells. This study evaluated whether the phospholipid-coated hollow calcium phosphate nanoparticles (LCP) could be used as a potential candidate for synergistic co-delivery drug system.

\section{Materials and methods}

\section{Materials}

PTX and DOX were provided by Xi' an Natural Field BioTechnique Co., Ltd. (Xi'an, China) and Hubei Yuancheng
Company (Hubei, China) with a purity $>99 \%$. Styrene (St) monomer, potassium persulfate $\left(\mathrm{K}_{2} \mathrm{~S}_{2} \mathrm{O}_{8}\right)$, anhydrous ethanol, tetrahydrofurane, and calcium chloride $\left(\mathrm{CaCl}_{2}\right)$ were purchased from Tianjin Yongsheng Fine Chemical Co., Ltd. (Tianjin, China). Ammonium dihydrogen phosphate $\left(\mathrm{NH}_{4} \mathrm{H}_{2} \mathrm{PO}_{4}\right)$ and dichloromethane were supplied by Tianjin Guangfu Fine Chemical Co., Ltd. (Tianjin, China). Soya lecithin was purchased from Shanghai Tywei Pharmaceutical Co., Ltd. (Shanghai, China), and cholesterol was purchased from Sinopharm Chemical Reagent Co., Ltd. (Shanghai, China). Fluorescein isothiocyanate (FITC) and rhodamine phalloidin were purchased from Beijing Dingguo Changsheng Biotechnology Co., Ltd. (Beijing, China) and trypsin was purchased from Genview (Beijing, China). Deionized water was used in all experiments.

\section{Synthesis of LCP}

\section{Step one}

Polystyrene (PS) nanospheres were prepared by soap-freeemulsion polymerization method. ${ }^{15}$ Briefly, $170 \mathrm{~mL} \mathrm{H}_{2} \mathrm{O}$ and $10 \mathrm{~mL} \mathrm{St} \mathrm{(with} \mathrm{removal} \mathrm{of} \mathrm{polymerization} \mathrm{inhibitor)}$ were added to a three-necked flask reactor. The mixture was then stirred at $120 \mathrm{rpm}$ under $70^{\circ} \mathrm{C}$, and $\mathrm{N}_{2}$ atmosphere was introduced for $10 \mathrm{~min} . \mathrm{K}_{2} \mathrm{~S}_{2} \mathrm{O}_{8}(0.007 \mathrm{~g} / \mathrm{mL}, 10 \mathrm{~mL})$ aqueous solution was added to the reaction solution and continuously stirred for $28 \mathrm{~h}$. The synthesized emulsion was cooled to room temperature and centrifuged at 10,000 rpm for $20 \mathrm{~min}$. Finally, the isolated precipitate (PS) was washed with water and anhydrous ethanol and dried at $50^{\circ} \mathrm{C}$.

The sulfonated PS nanospheres (SPS) were obtained as follows: $1 \mathrm{~g}$ of PS nanospheres was dispersed in $30 \mathrm{~mL}$ of concentrated sulfuric acid and sonicated for $1-2 \mathrm{~min}$. The mixture was then stirred at $40^{\circ} \mathrm{C}$ for $10 \mathrm{~h}$. The reaction system was then cooled to room temperature, and the product was centrifuged and washed with anhydrous ethanol repeatedly. After drying in a vacuum at $40^{\circ} \mathrm{C}$, SPS nanospheres were obtained. ${ }^{16}$

\section{Step two}

HCP was synthesized using SPS nanospheres as a colloidal crystal template. A certain amount of SPS nanospheres prepared in step 1 was dispersed in $100 \mathrm{~mL}$ of deionized water by ultrasonication. The suspension was stirred at room temperature. Subsequently, $1.2 \mathrm{~mL} \mathrm{NH_{4 }} \mathrm{H}_{2} \mathrm{PO}_{4}(0.1 \mathrm{~mol} / \mathrm{L})$ and $2 \mathrm{~mL} \mathrm{CaCl}_{2}(0.1 \mathrm{~mol} / \mathrm{L})$ were added. ${ }^{17,18}$ The mixture was allowed to react for $4-5 \mathrm{~h}$. The emulsion was centrifuged at $10,000 \mathrm{rpm}$ for $10 \mathrm{~min}$, and the precipitate was then washed with anhydrous ethanol and dried at $40^{\circ} \mathrm{C}$. The white fine powders obtained were soaked twice (at an interval of $12 \mathrm{~h}$ ) 
in tetrahydrofuran to remove template. Finally, HCP was obtained after washing with anhydrous ethanol three times and drying at $50^{\circ} \mathrm{C}$.

\section{Step three}

LCP was fabricated by thin-film hydration method. ${ }^{19}$ Soya lecithin/cholesterol mixture at a known molar ratio was dissolved in $5 \mathrm{~mL}$ of dichloromethane to form lipid film by a rotary evaporator at $25^{\circ} \mathrm{C}$. The film was hydrated with $5 \mathrm{~mL}$ of phosphate-buffered solution ( $\mathrm{PBS}, \mathrm{pH}=6.8$ ) containing HCP for $30 \mathrm{~min}$. The suspension was sonicated with a probe at a power output of $40 \mathrm{~W}$ for $20 \mathrm{~min}$. LCP was separated by centrifugation at $15,000 \mathrm{rpm}$ for $10 \mathrm{~min}$ and freeze-dried for further experiments.

\section{Drug-loading procedure}

PTX and DOX were selected as model drugs. At the beginning, DOX was loaded onto HCP by adsorption equilibrium method. About $250 \mathrm{mg} \mathrm{HCP}$ was soaked in $10 \mathrm{mg} / \mathrm{mL}$ DOX aqueous solution for $4 \mathrm{~h}$. The loading procedure was performed in closed containers in the dark at room temperature. The supernatant was removed by centrifugation at 6,000 rpm and the drug-loaded sample (DOX-HCP) was dried in a vacuum. PTX, soya lecithin, and cholesterol were dissolved in $5 \mathrm{~mL}$ dichloromethane to form drugloaded lipid film. The film was hydrated with $5 \mathrm{~mL}$ PBS ( $\mathrm{pH}=6.8$ ) containing DOX-HCP for $30 \mathrm{~min}$. The suspension was sonicated with a probe at a power output of $40 \mathrm{~W}$ for $20 \mathrm{~min}$. The drug-loaded sample (PTX/DOX-LCP) was then separated by centrifugation and freeze-dried. The preparation process of LCP containing only PTX or DOX (PTX-LCP, DOX-LCP) was the same as mentioned earlier. The loading capacity of PTX and DOX was determined by HPLC (L-2400, HITACHI, Tokyo, Japan) equipped with a Welch C18 column $(4.6 \times 200 \mathrm{~mm}, 5 \mu \mathrm{m})$ and UV spectroscopy (UV-2000, Unico Inc, Franksville, WI, USA) at $490 \mathrm{~nm}$, respectively.

\section{Evaluation of HCP coating process}

Measurements of particle size distribution and zeta potential

The preparation process of PTX/DOX-LCP was the same as mentioned earlier. The particle size, polydispersity index (PDI), and zeta potential were measured using Malvern Zetasizer (Nano-ZS90; Malvern Instruments Ltd., Malvern, UK) to obtain optimal coating process conditions. The analyses were performed at a scattering angle of $90^{\circ}$ at $25^{\circ} \mathrm{C}$, and the samples were appropriately diluted with distilled water.
Determination of encapsulation efficiency (EE) EE of PTX in PTX/DOX-LCP was measured for evaluating the coating process. The PTX of PTX/DOX-LCP was extracted with methanol and determined by HPLC (L-2400, HITACHI equipped with a Welch C18 column $(4.6 \times 200 \mathrm{~mm}$, $5 \mu \mathrm{m})$. The mobile phase was a mixture of acetonitrile and water $(50: 50, v / v)$, and detection was performed with a UV-vis detector at $237 \mathrm{~nm}$. The EE was calculated as follows:

$\begin{gathered}\text { Encapsulation } \\ \text { efficiency }(\%)\end{gathered}=\frac{\text { Amount of PTX present in LCP }}{\text { Total amount of PTX }}$

\section{Characterization of LCP and PTX/ DOX-LCP}

The structure and morphology of SPS nanospheres, HCP, and LCP were characterized by transmission electron microscopy (TEM; Tecnai G2F30; FEI Co, Hillsboro, OR, USA, operated at $200 \mathrm{kV}$ ). Drug crystallinity was examined using differential scanning calorimeter (DSC; DSC-60; Shimadzu, Kyoto, Japan) at a constant heating rate of $10^{\circ} \mathrm{C} / \mathrm{min}$ ranging from $30^{\circ} \mathrm{C}$ to $240^{\circ} \mathrm{C}$ under a constant nitrogen flow of $150 \mathrm{~mL} / \mathrm{min}$. Powder $\mathrm{X}$-ray diffractometer (PXRD; Rigaku Geigerflex XRD, Co., Tokyo, Japan, $\mathrm{Cu}-\mathrm{Ka}$ radiation, $30 \mathrm{kV}$ and $30 \mathrm{~mA}$ ) was used to further investigate the physical state of PTX and DOX with the following parameters: step size of $0.02^{\circ}$, scanning rate of $4^{\circ} \%$ min, and range $(2 \theta)$ from $3^{\circ}$ to $60^{\circ}$. Fourier-transform infrared (FT-IR) spectra were recorded using FT-IR spectrometer ranging from 400 to $4,000 \mathrm{~cm}^{-1}$ (Bruker IFS 55; Bruker, Billerica, $\mathrm{MA}, \mathrm{USA}$ ) and $\mathrm{KBr}$ pellet technique.

\section{In vitro drug-release study}

PTX/DOX-LCP powders (containing $0.78 \mathrm{mg}$ PTX and $9.70 \mathrm{mg}$ DOX) were dispersed in $200 \mathrm{~mL}$ PBS ( $\mathrm{pH}=6.8$ ) release medium. The test was operated at $37^{\circ} \mathrm{C} \pm 0.5^{\circ} \mathrm{C}$, with a paddle speed of $100 \mathrm{rpm}$. At predetermined time points, $5 \mathrm{~mL}$ of samples was withdrawn and replaced with $5 \mathrm{~mL}$ of fresh release medium. The filtrate was passed through a 0.45 $\mu \mathrm{m}$ microporous membrane filter and used as the test sample. The concentration of DOX was analyzed by UV spectroscopy (UV-2000; Unico Inc.) at $490 \mathrm{~nm}$. The amount of PTX was measured at $237 \mathrm{~nm}$ by HPLC (L-2400; HITACHI) with a Welch C18 column $(4.6 \times 200 \mathrm{~mm}, 5 \mu \mathrm{m})$. Acetonitrile-water $(50: 50, \mathrm{v} / \mathrm{v})$ was used as mobile phase.

\section{In vitro cytotoxicity}

\section{Combinational effects of DOX and PTX}

A549 cell lines were purchased from Jiangsu KeyGEN BioTECH Corp., Ltd. A549 cells were cultured in RMPI 
1640 medium with $10 \%(\mathrm{v} / \mathrm{v})$ heat-inactivated fetal bovine serum at $37^{\circ} \mathrm{C}$ under $5 \% \mathrm{CO}_{2}$. A549 cells were seeded into 96-well plates at $1 \times 10^{4}$ cells/well and incubated at $37^{\circ} \mathrm{C}$ for $24 \mathrm{~h}$. The combinations of DOX and PTX at various mass ratios were represented as follows: $\mathrm{DOX} / \mathrm{PTX}=\mathrm{x} / \mathrm{y}$, where $\mathrm{x} / \mathrm{y}$ denotes the mass ratio of DOX/PTX in combination. Graded concentrations of drug solution (free DOX, free PTX, DOX/PTX =12/1, DOX/PTX =6/1, DOX/PTX =3/1, $\mathrm{DOX} / \mathrm{PTX}=1 / 3$, and DOX/PTX =1/6) were added to wells and cultured for $24 \mathrm{~h}$. Subsequently, MTT reagent $(20 \mu \mathrm{L}$, $5 \mathrm{mg} / \mathrm{mL}$ ) was added, and the cells were cultured for an additional $4 \mathrm{~h}$. The supernatant was then removed and the medium was replaced with $200 \mu \mathrm{L}$ DMSO. After shaking for $10 \mathrm{~min}$, the absorbance was measured at $492 \mathrm{~nm}$ using a microplate reader (Tecan, Mannedorf, Switzerland). The cell viability was determined by comparing treated cells with untreated cells using the following formula: ${ }^{20}$

$$
\text { Cell viability }(\%)=\frac{\mathrm{A}_{\text {sample }}}{\mathrm{A}_{\text {control }}} \times 100 \%
$$

where $\mathrm{A}_{\text {sample }}$ and $\mathrm{A}_{\text {control }}$ denote the absorbance of treated cells and untreated cells, respectively.

\section{Cell viability}

The cell viability of A549 cells treated with LCP was determined as described earlier. A physical mixture (PM) of free DOX and free PTX (DOX/PTX, which had the same proportion as PTX/DOX-LCP) and PTX/DOX-LCP were dispersed in hydroxypropyl methylcellulose (HPMC) solution for MTT analysis.

\section{Flow cytometry assays}

Apoptosis analysis was conducted using Annexin V-FITC and PI apoptosis kit (Nanjing Jiancheng Bioengineering Institute, Nanjing, China). A549 cells were seeded in 6-well plates at $1 \times 10^{5}$ cells/well and incubated at $37^{\circ} \mathrm{C}$ for $24 \mathrm{~h}$. The cells treated with DOX/PTX and PTX/DOX-LCP for $48 \mathrm{~h}$ were harvested by trypsinization. The harvested cells were dispersed in $500 \mu \mathrm{L}$ of binding buffer, and $5 \mu \mathrm{L}$ of Annexin V-FITC and $5 \mu \mathrm{L}$ of PI (Nanjing Jiancheng) were then added and mixed for $15 \mathrm{~min}$. Finally, apoptosis status of A549 cells was observed by flow cytometry (Becton Dickinson, Franklin Lakes, NJ, USA).

\section{Cellular uptake study}

LCP was prepared by substituting DOX loaded into HCP with FITC (FITC-LCP). FITC-LCP was used for confocal laser scanning microscopy (CLSM; Leica Microsystems, Wetzlar,
Germany) observation. A549 cells were seeded in 6-well plates at $5 \times 10^{5}$ cells/well and incubated at $37^{\circ} \mathrm{C}$ for $24 \mathrm{~h}$. FITC-LCP was added to wells at a concentration of $25 \mu \mathrm{g} / \mathrm{mL}$. After various times, the medium was removed and cells were washed three times with PBS. The cells were then fixed with $4 \%$ paraformaldehyde for $10 \mathrm{~min}$ and rinsed with PBS, and $1 \mathrm{~mL}$ of $0.1 \%$ Triton X-100 was added to the wells for $10 \mathrm{~min}$ followed by a PBS wash. Subsequently, $1 \mathrm{~mL}$ of $1 \%$ bovine serum albumin was added for $30 \mathrm{~min}$ followed by three PBS washes. Ultimately, the cells were stained with $1 \mu \mathrm{g} / \mathrm{mL}$ Hoechst 33342 for $20 \mathrm{~min}$ and $1 \mu \mathrm{g} / \mathrm{mL}$ rhodamine phalloidin for $30 \mathrm{~min}$. Meanwhile, FITC-LCP at different concentrations (20, 25, and $50 \mu \mathrm{g} / \mathrm{mL}$ ) was cultured for $1 \mathrm{~h}$ according to the aforementioned methods. The samples were observed by CLSM (Leica).

\section{TEM analysis of cellular uptake}

A549 cells were seeded in 6 -well plates at $5 \times 10^{5}$ cells/well and incubated at $37^{\circ} \mathrm{C}$ for $24 \mathrm{~h}$. LCP $(50 \mu \mathrm{g} / \mathrm{mL})$ was then added to the wells. After $3 \mathrm{~h}$ of incubation, the medium was removed and the cells were washed three times with PBS. The washed cells were collected and fixed with $3 \%$ glutaraldehyde solution for $24 \mathrm{~h}$ at $4^{\circ} \mathrm{C}$. The cells were then embedded into $2 \%$ agarose gel followed by fixation with $1 \%$ osmium tetroxide solution. After dehydration, the cells were embedded into epoxy resin. The resin blocks were polymerized at $37^{\circ} \mathrm{C}, 45^{\circ} \mathrm{C}$, and $60^{\circ} \mathrm{C}$ for $24 \mathrm{~h}$. Ultrathin sections were obtained by an ultramicrotome (EMUC6; Leica) and observed by TEM.

\section{In vivo anti-tumor efficacy}

In vivo anti-tumor efficacy was evaluated using subcutaneous A549 tumor-bearing nude mice (Beijing Weitong Lihua Experimental Animal Technology Co. Ltd.). The animal experiment was conducted in accordance with the guidelines of the Institutional Animal Care and Use Committee of Liaoning Medical University and approved by the committee (No 11400700217882). The tumor-bearing mice were subcutaneously implanted with $0.1 \mathrm{~mL}$ of physiological saline containing $5 \times 10^{4}$ A549 cells in the left and right hind legs. Drug administration began when the tumor volume reached $\sim 50-70 \mathrm{~mm}^{3}$ (set as 0 days). The tumor-bearing mice were randomly divided into the following three groups: physiological saline, DOX/PTX, and PTX/DOX-LCP. The mice were administered $0.45 \mu \mathrm{mol} / \mathrm{L}$ of total drugs every 3 days. Tumor size was measured by a caliper, and tumor volume was estimated using the following equation: ${ }^{21}$

$$
V=0.5 \times \text { length } \times(\text { width })^{2}
$$


After dosing for 15 days, the animals were killed by cervical dislocation and solid tumors were excised and photographed. Subsequently, the solid tumors were fixed with paraformaldehyde, embedded into paraffin, and sectioned. Each section was stained by hematoxylin and eosin (H\&E) and then observed under a fluorescent microscope (Leica DMI 4000B; Leica).

\section{Determination of $\mathrm{Bax}, \mathrm{Bcl}-2$, and Caspase-3 protein expression levels}

Total protein was extracted from tumor tissues by ultrasonic grinding. Protein concentrations were adjusted to a certain value as determined by the bicinchoninic acid method. In accordance with method of the "molecular cloning experiment guide" (second edition), the concentrated and separation gels were prepared. The protein samples and the buffer solution were mixed at a ratio of 4:1 and the solution was boiled for $5 \mathrm{~min}$. The samples $(10 \mu \mathrm{L})$ and the standard protein were subjected to SDS-PAGE electrophoresis at a voltage of $90 \mathrm{~V}$. After electrophoresis, the proteins were transferred to polyvinylidene difluoride membranes and then blocked with tris-buffered saline tween buffer (TBST) containing $5 \%$ skim milk for $1 \mathrm{~h}$. The membranes were then incubated overnight with primary antibodies. After three TBST washes, the membranes were incubated with secondary antibodies for at least $2 \mathrm{~h}$, and they were then washed three times with TBST. Enhanced chemiluminescence reagents and X-ray film were used to develop the blots in a darkroom, and blot analysis was performed by Pro Analyzer 4.0 software (BioRad Laboratories Inc.).

\section{Results and discussion Evaluation of HCP coating process}

The phospholipid-coating process was optimized by orthogonal method to obtain the optimal formulation. Pre-experiments results indicated that there was some loss of DOX absorbed in HCP during coating process, but the drug loading of DOX was almost identical after coating process. Therefore, DOX loading had no effect on the coating process. Three factors, namely the soya lecithin/cholesterol molar ratio, DOXHCP concentration, and PTX concentration, were selected to optimize PTX/DOX-LCP preparation procedure. ${ }^{22}$

Particle size, PDI, zeta potential, and EE of PTX in PTX/ DOX-LCP are listed in Table 1. PTX/DOX-LCP showed a larger particle size than LCP. This was because PTX was loaded into LCP so that the particle size was slightly increased. As the concentration of PTX increased from 10 to $30 \mathrm{mg}$, the particle size of PTX/DOX-LCP gradually
Table I Characterization of PTX/DOX-LCP with different prescriptions $(n=3)$

\begin{tabular}{llllll}
\hline Formulation & Prescription & $\begin{array}{l}\text { Particle } \\
\text { size } \\
(\mathbf{n m})\end{array}$ & $\begin{array}{l}\text { PDI } \\
\text { Zeta } \\
\text { potential } \\
(\mathbf{m V})\end{array}$ & EE (\%) \\
\hline HCP & - & 257.3 & $0.187-$ & - \\
LCP & $\mathrm{A}_{2} \mathrm{~B}_{2}$ & 297.8 & 0.259 & -40.1 & - \\
PTX/DOX-LCPI & $\mathrm{A}_{1} \mathrm{~B}_{1} \mathrm{C}_{1}$ & 300.1 & 0.016 & -29.6 & 63.14 \\
PTX/DOX-LCP2 & $\mathrm{A}_{1} \mathrm{~B}_{2} \mathrm{C}_{3}$ & 311.5 & 0.084 & -36.2 & 56.43 \\
PTX/DOX-LCP3 & $\mathrm{A}_{1} \mathrm{~B}_{3} \mathrm{C}_{2}$ & 308.0 & 0.100 & -16.8 & 60.61 \\
PTX/DOX-LCP4 & $\mathrm{A}_{2} \mathrm{~B}_{1} \mathrm{C}_{3}$ & 348.7 & 0.211 & -39.8 & 78.92 \\
PTX/DOX-LCP5 & $\mathrm{A}_{2} \mathrm{~B}_{2} \mathrm{C}_{2}$ & 335.0 & 0.228 & -41.1 & 80.40 \\
PTX/DOX-LCP6 & $\mathrm{A}_{2} \mathrm{~B}_{3} \mathrm{C}_{1}$ & 313.4 & 0.062 & -40.1 & 79.95 \\
PTX/DOX-LCP7 & $\mathrm{A}_{3} \mathrm{~B}_{1} \mathrm{C}_{2}$ & 389.1 & 0.134 & -37.3 & 66.83 \\
PTX/DOX-LCP8 & $\mathrm{A}_{3} \mathrm{~B}_{2} \mathrm{C}_{1}$ & 371.2 & 0.390 & -38.3 & 78.71 \\
PTX/DOX-LCP9 & $\mathrm{A}_{3} \mathrm{~B}_{3} \mathrm{C}_{3}$ & 473.8 & 0.048 & -42.1 & $65.4 \mathrm{I}$ \\
\hline Note A m & &
\end{tabular}

Notes: $A$, molar ratio of soya lecithin/cholesterol ( $\left.A_{1}, 3: 1 ; A_{2}, 4: 1 ; A_{3}, 5: I\right)$; $B$, the concentration of DOX-HCP ( $\left.B_{1}, 100 \mathrm{mg} ; B_{2}, 200 \mathrm{mg} ; B_{3}, 300 \mathrm{mg}\right)$; $C$, the concentration of PTX ( $\left.C_{1}, 10 \mathrm{mg} ; C_{2}, 20 \mathrm{mg} ; C_{3}, 30 \mathrm{mg}\right)$. '-' indicates absence of data. Abbreviations: HCP, hollow calcium phosphate; LCP, lipid-coated hollow calcium phosphate; DOX, doxorubicin; PTX, paclitaxel; PDI, polydispersity index; EE, encapsulation efficiency.

increased. However, the EE of PTX decreased when the concentration of PTX reached $30 \mathrm{mg}$. Thus, the maximum concentration of PTX loaded into lipid bilayer was $20 \mathrm{mg}$. PTX-LCP5 with soya lecithin/cholesterol at a molar ratio of 4:1, $200 \mathrm{mg}$ DOX-HCP, and $20 \mathrm{mg}$ PTX showed optimal particle size $(335.0 \pm 3.2 \mathrm{~nm})$ and high $\mathrm{EE}(80.40 \% \pm 2.24 \%)$. Therefore, the optimized PTX-LCP5 was selected as the best formulation for further experiments.

The loading capacity was calculated using the following formula: ${ }^{23}$

$$
\begin{aligned}
& \text { Loading capacity }(\%)= \\
& \frac{\text { Amount of drug in LCP }}{\text { Total amount of the drug - Loaded sample }}
\end{aligned}
$$

The loading capacities of PTX and DOX were $3.81 \% \pm 0.13 \%$ and $45.96 \% \pm 0.27 \%$, respectively, which suggested that HCP had a high adsorption capacity and was suitable to be used as a carrier of drugs. More importantly, the real mass ratio of DOX and PTX in PTX/DOX-LCP was 12:1, thus conforming to synergistic ratio. Therefore, LCP was regarded as a promising carrier for synergistic co-delivery of DOX and PTX, based on water solubility, optimal dose ratio of synergistic co-delivery, and drug-loading capacity.

\section{Morphology and structure}

The morphology and structure of SPS nanospheres, HCP, and LCP were observed by TEM. As shown in Figure 1A, the average diameter of monodispersed SPS colloidal crystal template was $257 \mathrm{~nm}$. After sulfonation, the negatively charged sulfonic 

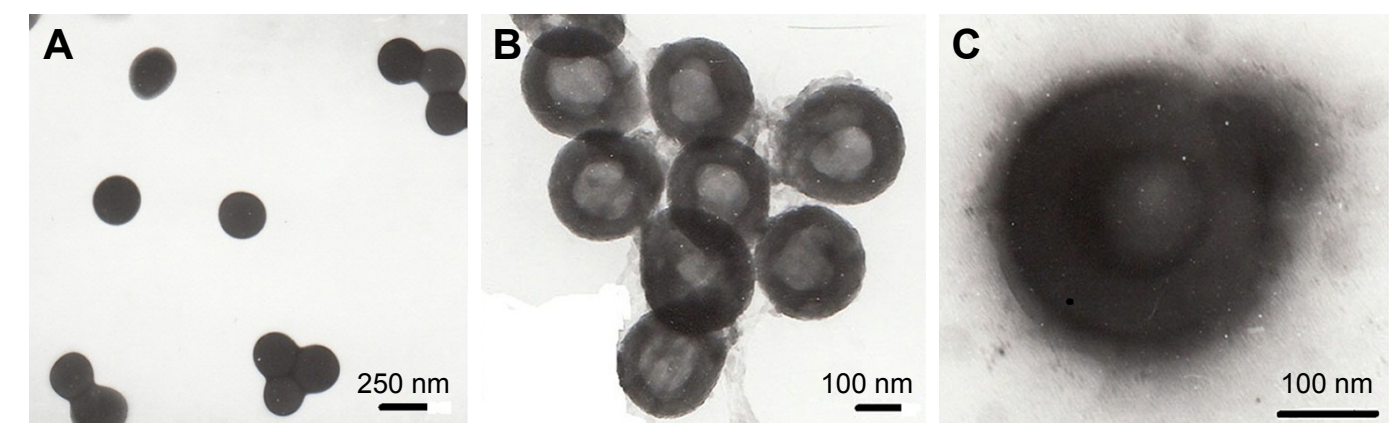

Figure I TEM images of SPS nanospheres (A), HCP (B), and LCP (C). Magnification $\times 30,000$.

Abbreviations: TEM, transmission electron microscopy; SPS, sulfonated polystyrene nanospheres; HCP, hollow calcium phosphate; LCP, lipid-coated hollow calcium phosphate.

acid groups were exposed on the surface of PS nanospheres to attract the positively charged $\mathrm{Ca}^{2+}$ ions through electrostatic adsorption. Subsequently, addition of $\mathrm{PO}_{4}{ }^{3-}$ ions caused $\mathrm{CaP}$ precipitation to deposit on the surface of SPS nanospheres. The HCP displayed a hollow structure after removing the SPS template (Figure 1B), which was suitable for the storage of poorly soluble drugs or water-soluble drugs. The hollow structure could allow highly uniform drug dispersion and improve drug stability due to the protective effect of shell structure. Moreover, for poorly water-soluble drugs, the hollow structure could also effectively decrease drug particle size and reduce drug crystallinity. According to the Ostwald-Freundlich equation, a decrease in the drug particle size and an increase in the specific surface area would improve the drug solubility. ${ }^{24}$ A lipid bilayer could allow the introduction of poorly watersoluble drugs in a certain ratio to achieve co-delivery of drugs. Figure 1C shows that lipid was homogenously coated on the surface of HCP nanoparticles. Thus, LCP nanoparticles had great potential as co-delivery drug carriers.

\section{In vitro cytotoxicity assay}

\section{Combinational effects of DOX and PTX}

To determine the ideal ratio of DOX and PTX in LCP for in vitro and in vivo experiments, MTT assay was conducted to investigate the combinational effects of DOX and PTX. The inhibitory concentration to produce $50 \%$ cell death $\left(\mathrm{IC}_{50}\right)$, combination index $\left(\mathrm{CI}_{50}\right)$, and dose-reduction index (DRI) of different compositions (free DOX, free PTX, DOX/PTX =12/1, DOX/PTX =6/1, DOX/PTX =3/1, $\mathrm{DOX} / \mathrm{PTX}=1 / 3$, and DOX/PTX $=1 / 6$ ) are shown in Table 2. When DOX was the predominant drug in the combination therapy, the $\mathrm{IC}_{50}$ values of DOX were lower than that of free DOX treatment. At the same time, the DRI values were all greater than 1, representing a reduction in dose and toxicity as well as synergistic effect. However, when PTX was the predominate drug in the combination therapy, the $\mathrm{IC}_{50}$ values of PTX were more than that of free PTX treatment. The $\mathrm{CI}_{50}$ values were less than 1 when DOX was the predominate drug, and DOX and PTX displayed a synergistic effect. ${ }^{25}$ In conclusion, DOX and PTX with a mass ratio of 12:1 showed an excellent synergistic effect, which agreed with the literature. According to the literature, when the molar ratio of DOX and PTX was greater than 1:1, the combination therapy displayed a synergistic effect. ${ }^{7}$

\section{Cell viability}

Figure 2 shows the cell viability of LCP at various concentrations (from $10 \mu \mathrm{g} / \mathrm{mL}$ to $500 \mu \mathrm{g} / \mathrm{mL}$ ). The cell viability of A549 cells was $>95 \%$ at the highest concentration $(500 \mu \mathrm{g} / \mathrm{mL})$, which demonstrated that LCP was nontoxic. The PTX/DOX-LCP exhibited a higher inhibition rate than DOX/PTX. These results indicated that LCP, as a co-delivery drug carrier, could improve absorption of PTX and DOX as well as enhance the effects of drugs. This effect was related to the inhibition of cell growth. Figure 2B shows that the $\mathrm{IC}_{50}$ values of PTX and DOX in DOX/PTX $(42.65 \mathrm{ng} / \mathrm{mL}$, $486.93 \mathrm{ng} / \mathrm{mL}$ ) were slightly higher than that of PTX and DOX in PTX/DOX-LCP (36.31 ng/mL, $413.18 \mathrm{ng} / \mathrm{mL})$. It was obvious that the solubility of DOX remained unchanged

Table $2 \mathrm{IC}_{50}, \mathrm{Cl}_{50}$, and DRI of different compositions to A549 cells

\begin{tabular}{|c|c|c|c|c|}
\hline Compositions & $I C_{50}(\mathrm{ng} / \mathrm{mL})$ & $\mathrm{Cl}_{50}$ & $\begin{array}{l}\text { DRI for } \\
\text { DOX }\end{array}$ & $\begin{array}{l}\text { DRI for } \\
\text { PTX }\end{array}$ \\
\hline DOX & 407.38 & - & - & - \\
\hline DOX/PTX $=12 / I$ & II2.20/9.33 & 0.61 & 3.64 & 3.02 \\
\hline DOX/PTX =6/I & $109.65 / 18.20$ & 0.92 & 3.72 & 1.55 \\
\hline $\mathrm{DOX} / \mathrm{PTX}=3 / \mathrm{I}$ & $69.18 / 22.91$ & 0.98 & 5.88 & 1.23 \\
\hline $\mathrm{DOX} / \mathrm{PTX}=\mathrm{I} / 3$ & $64.57 / 194.98$ & 7.08 & 6.29 & 0.14 \\
\hline $\mathrm{DOX} / \mathrm{PTX}=1 / 6$ & $39.81 / 239.88$ & 8.61 & 10.20 & 0.12 \\
\hline PTX & 28.18 & - & - & - \\
\hline
\end{tabular}

Note: '-' indicates absence of data.

Abbreviations: DOX, doxorubicin; PTX, paclitaxel; DRI, dose-reduction index; $\mathrm{IC}_{50}$, the inhibitory concentration to produce $50 \%$ cell death; $\mathrm{Cl}_{50}$, combination index. 

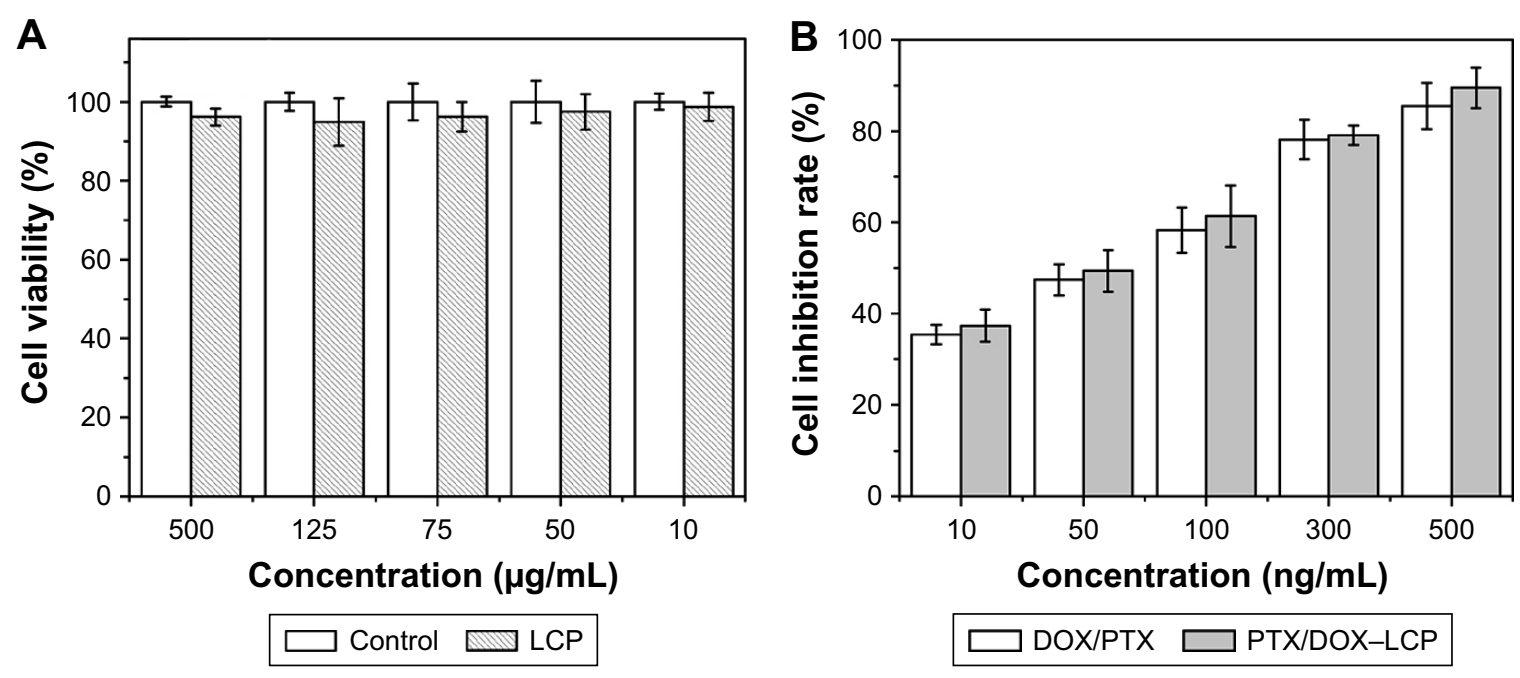

Figure 2 (A) Cell viability of LCP at various concentrations and (B) cell inhibition rate of PTX/DOX-LCP and DOX/PTX. Abbreviations: LCP, lipid-coated hollow calcium phosphate; DOX, doxorubicin; PTX, paclitaxel.

in the two groups as DOX was a water-soluble drug. However, PTX remained a poorly water-soluble drug in HPMC solution, which resulted in PTX being in a non-ideal dissolved state in the cell viability experiment. Thus, the ratio of DOX and PTX in the actual state was greater, and according to the conclusion of the combinational effect study, effects of PTX/DOX and PTX/DOX-LCP for A549 cells were more pronounced. For poorly water-soluble drugs, this was in line with the actual state of preparation.

\section{In vitro drug-release study}

As shown in Figure 3A, the PTX/DOX-LCP showed a sustained-release behavior for drugs. The concentration of dissolved PTX in PBS ( $\mathrm{pH}=6.8$ ) release medium reached $\sim 78 \%$ at 2 days, while the corresponding concentration was $58 \%$ for DOX. The release of PTX was slightly faster than that of DOX. The reason for this result was that the shell structure and phospholipid layer as the double barriers significantly increased the drug diffusion resistance. A sustained-release effect could maintain an effective drug concentration for a long time, prolong the time of drug action, improve curative effects, and reduce side effects.

\section{PXRD, DSC, and FTIR characterization}

The PXRD and DSC patterns were measured to confirm the change in drug crystallinity. ${ }^{26}$ The PXRD patterns of PTX, DOX, HCP, LCP, PTX-LCP, DOX-LCP, PTX/DOX-LCP and the same proportion of PM are shown in Figure 3B. PTX and DOX displayed many diffraction peaks, which indicated that PTX and DOX were crystalline drugs. The pure PTX and DOX showed distinctive characteristic diffraction peaks at $12^{\circ}$ and $22^{\circ}$, respectively. PTX-LCP did not show any crystalline diffraction pattern compared with pure PTX, which indicated that PTX was loaded into LCP and in an amorphous form as PTX was dispersed in lipid bilayer as molecular state. The crystalline diffraction pattern was markedly weakened in DOX-LCP compared to pure DOX. This showed that DOX loaded into LCP was in a microcrystalline state. The spatial confinement effect of hollow structure could effectively decrease drug particle size and reduce drug crystallinity. However, its diameter size was $257 \mathrm{~nm}(>60 \mathrm{~nm})$. According to relevant literatures, ${ }^{27-31}$ drugs absorbed in mesoporous state usually were in amorphous form, while drugs absorbed in macroporous state usually were dispersed in microcrystalline form. Therefore, PTX was in an amorphous state and DOX was in a microcrystalline form in PTX/DOX-LCP. But a change in the state of DOX did not change its solubility.

The DSC results were consistent with those of the PXRD characterization. As shown in Figure 3C, pure PTX and pure DOX produced a single sharp endothermic peak at $\sim 220^{\circ} \mathrm{C}$. The endothermic peak disappeared in PTX-LCP and was reduced in DOX-LCP. These data further confirmed that PTX absorbed onto LCP was in an amorphous state and that DOX was in a microcrystalline form.

The FT-IR spectra were used to investigate the chemical groups on the surface of the materials and analyze the interaction between drugs and LCP. ${ }^{32}$ The FTIR spectra of PTX, DOX, HCP, LCP, PTX-LCP, DOX-LCP, PTX/DOX-LCP, and PM are shown in Figure 3D. The FTIR patterns of PTX/ DOX-LCP and PM were coincident, which indicated that the drugs and LCP did not interact with each other.

\section{Apoptosis analysis}

As shown in Figure 4, PTX/DOX-LCP (74.2\%) and DOX/PTX (53.5\%) induced apoptosis compared to the control 
A
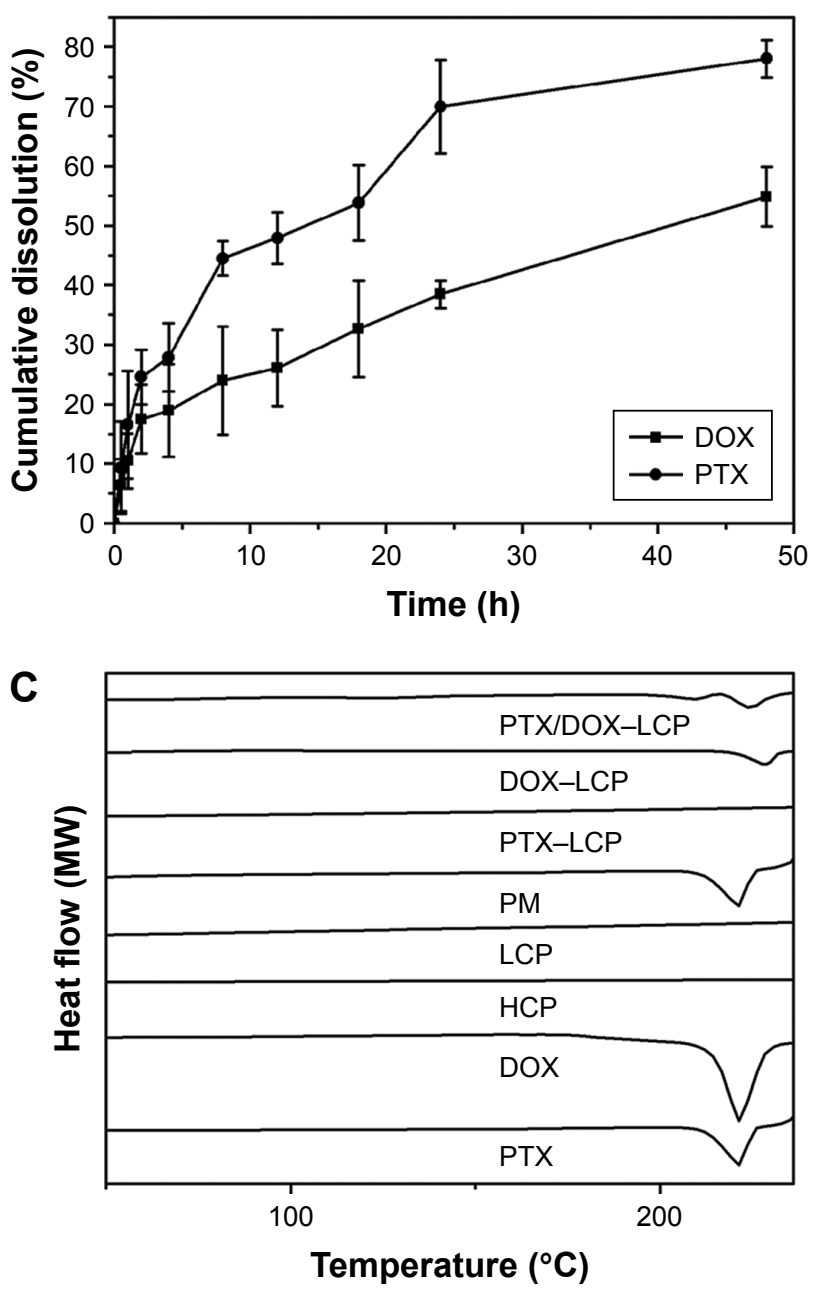

B
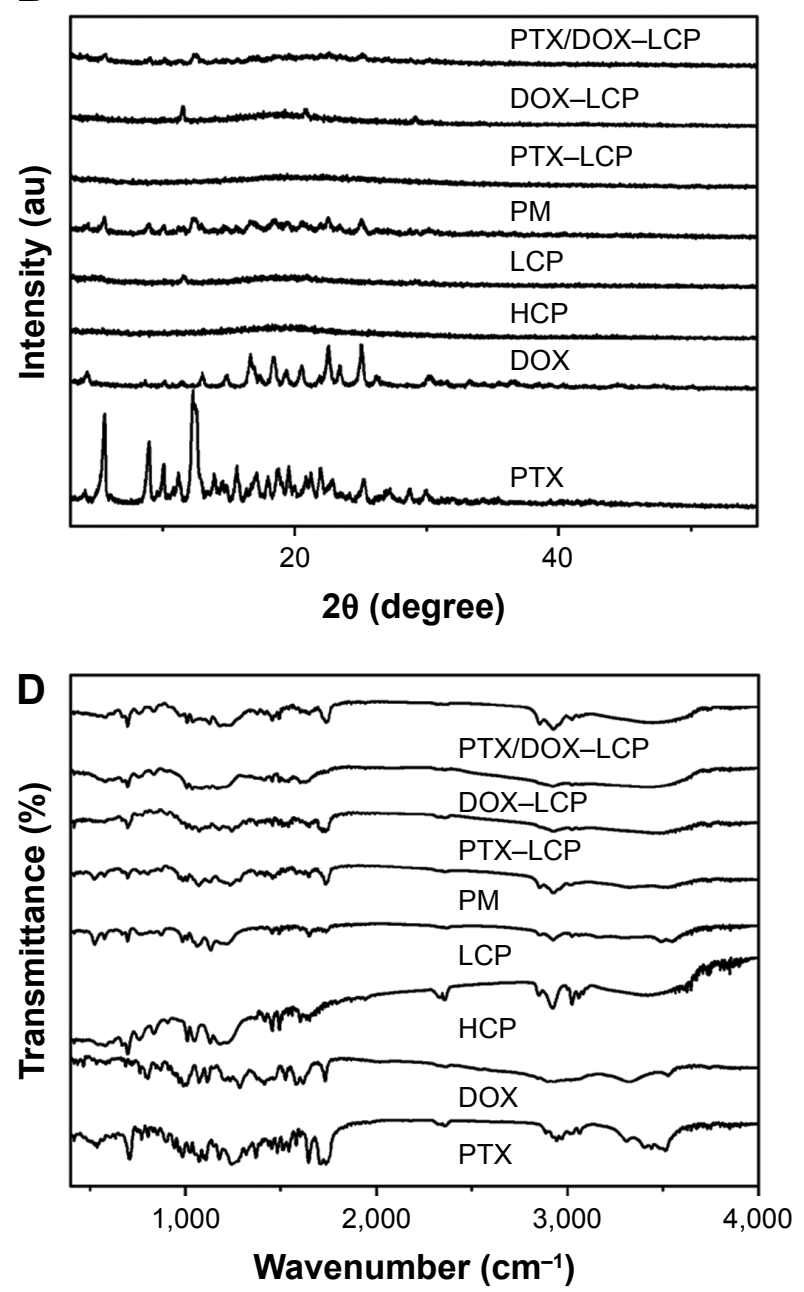

Figure 3 (A) In vitro drug-release curves of PTX/DOX-LCP powders. (B-D) The PXRD patterns, DSC patterns, and FT-IR spectra of PTX, DOX, HCP, LCP, PTX-LCP, DOX-LCP, and the physical mixture (PM) with the same proportion of PTX/DOX-LCP and PTX/DOX-LCP.

Abbreviations: LCP, lipid-coated hollow calcium phosphate; DOX, doxorubicin; PTX, paclitaxel; PXRD, powder X-ray diffractometer; DSC, differential scanning calorimeter; FT-IR, Fourier-transform infrared; HCP, hollow calcium phosphate.

group (15.6\%). DOX binds to DNA and topoisomerase II and PTX stabilizes microtubule complexes to promote cell apoptosis. These two factors worked in synergy to promote cell apoptosis. In the control group, the majority of A549 cells were observed in the first quadrant as shown in Figure 5A. As seen in Figure 5B and C, the number of early apoptotic cells increased in DOX/PTX and PTX/DOX-LCP groups. PTX/DOX-LCP led to the highest degree of apoptosis, which was due to improvement in drug absorption and enhancement of curative effect by means of the LCP carrier.

\section{Cell uptake study}

CLSM was conducted to test if FITC-LCP could be effectively taken up by A549 cells. Figure 6A exhibits the images of A549 cells treated with FITC-LCP at various time periods.

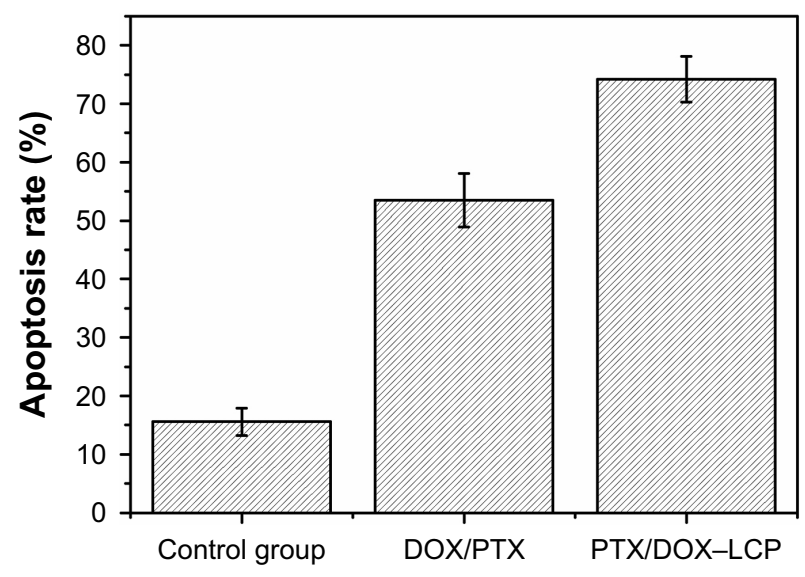

Figure 4 Apoptosis rate images of the control, DOX/PTX, and PTX/DOX-LCP groups.

Abbreviations: LCP, lipid-coated hollow calcium phosphate; DOX, doxorubicin; PTX, paclitaxel. 

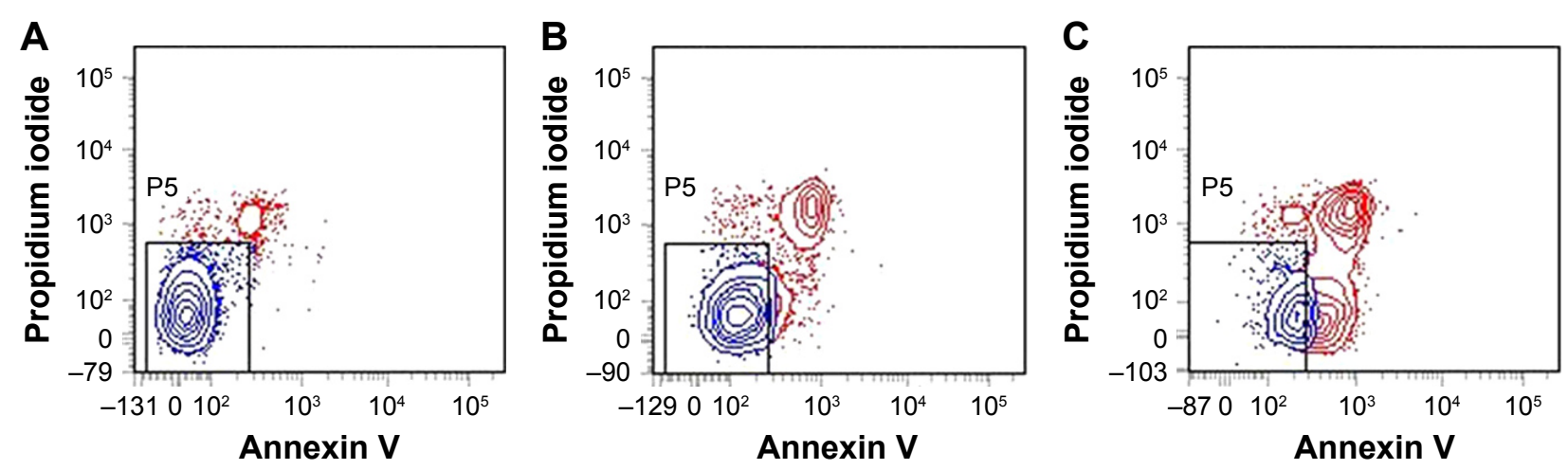

Figure $\mathbf{5}$ The flow cytometry images of the control group (A), DOX/PTX group (B), and PTX/DOX-LCP group (C). Abbreviations: LCP, lipid-coated hollow calcium phosphate; DOX, doxorubicin; PTX, paclitaxel.

A
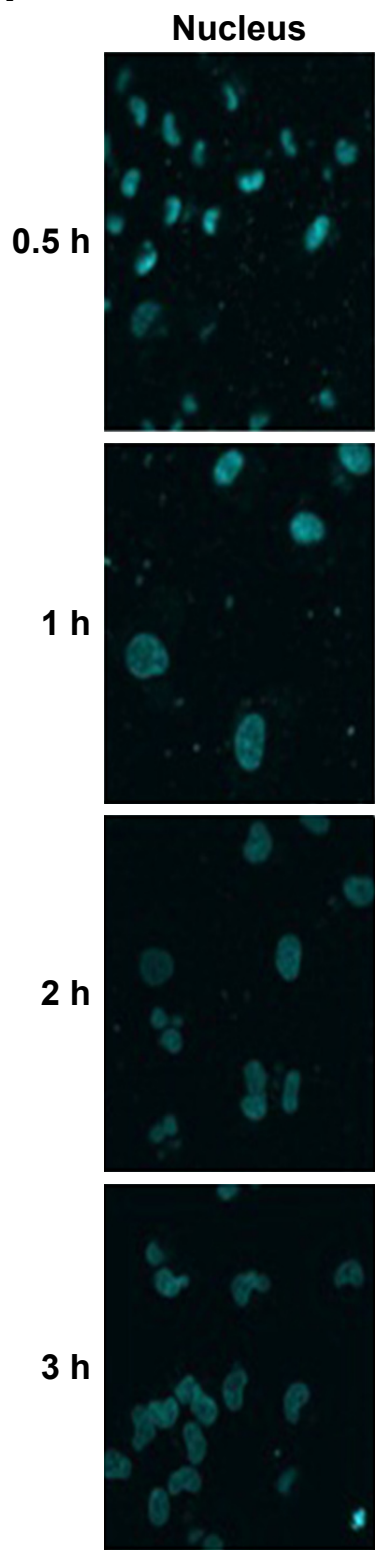

FITC-LCP
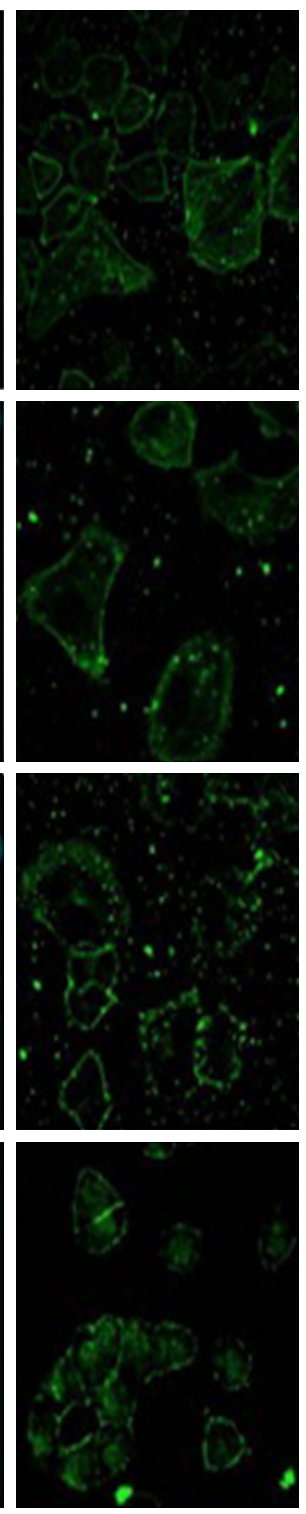

Rhodamine phalloidin
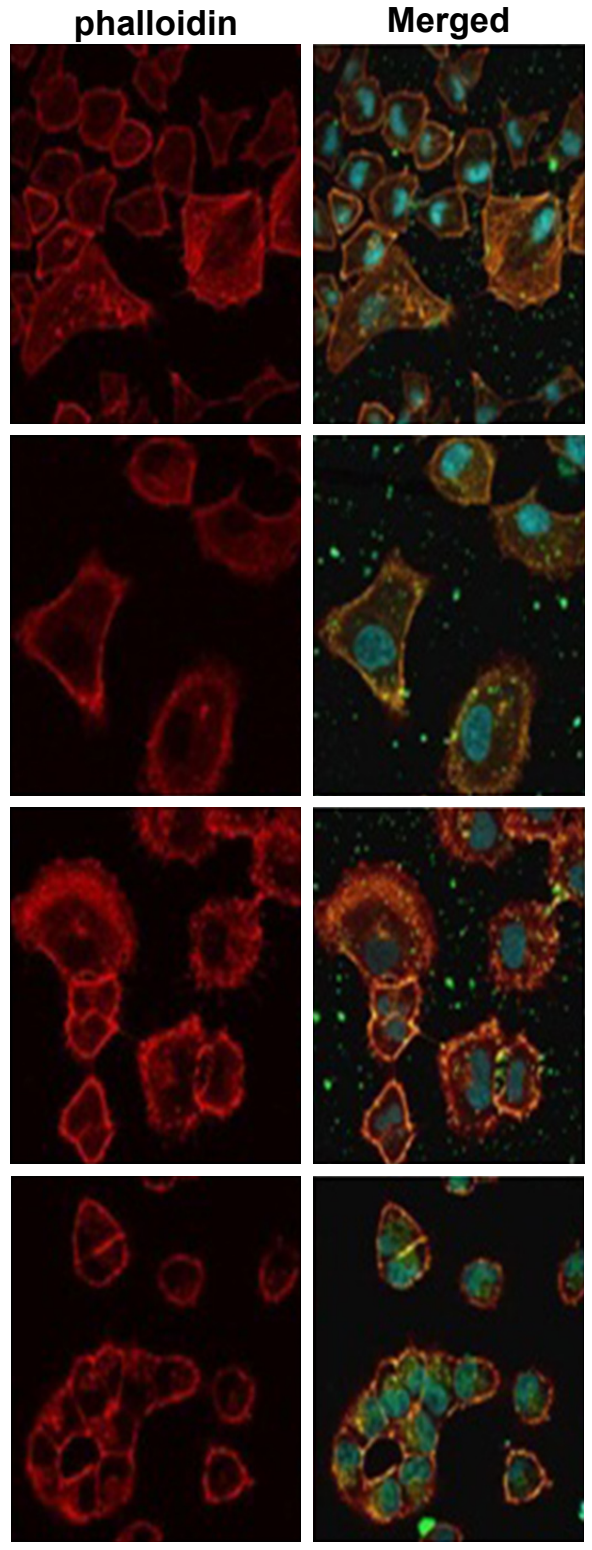

Figure 6 (Continued) 
B
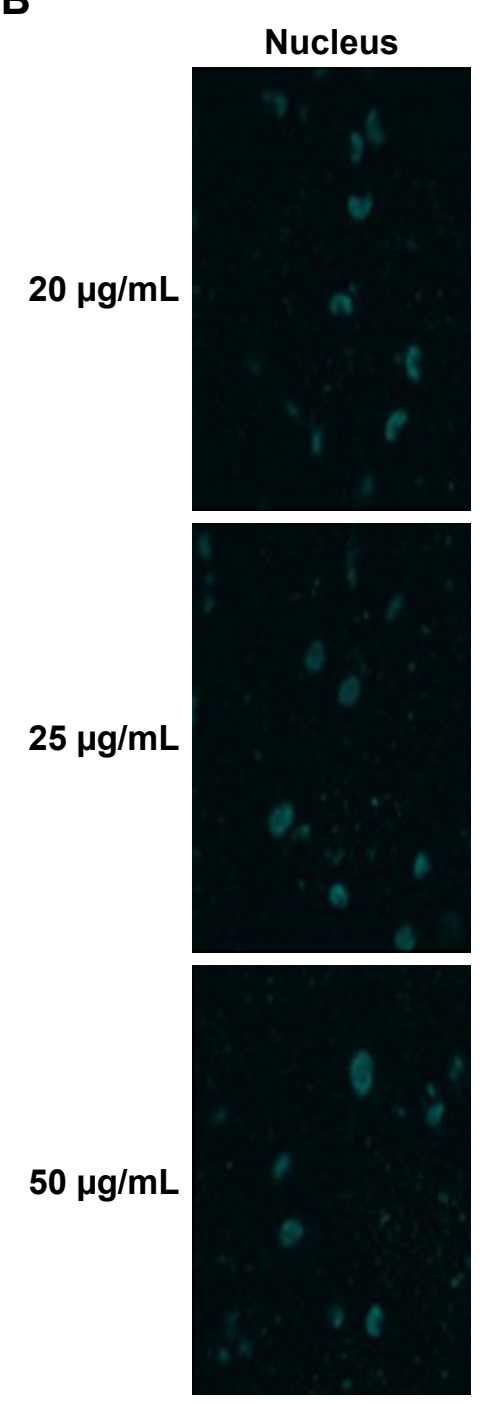

FITC-LCP
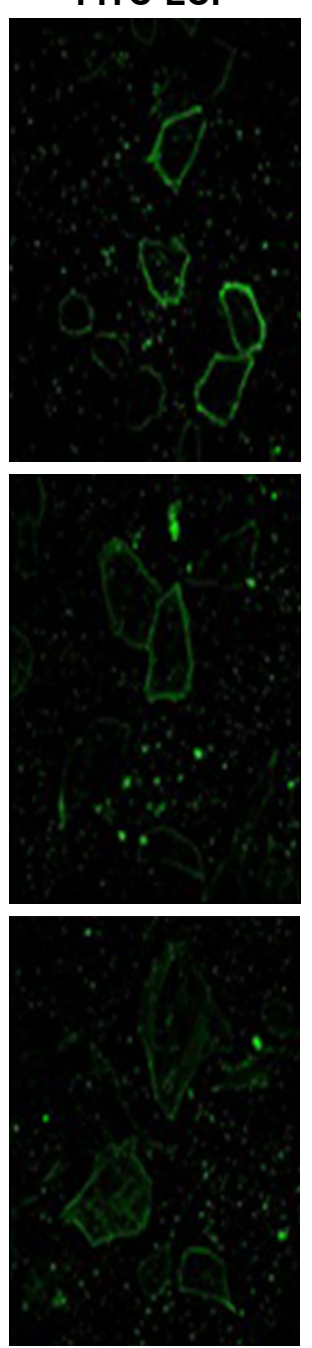

\section{Rhodamine}

phalloidin
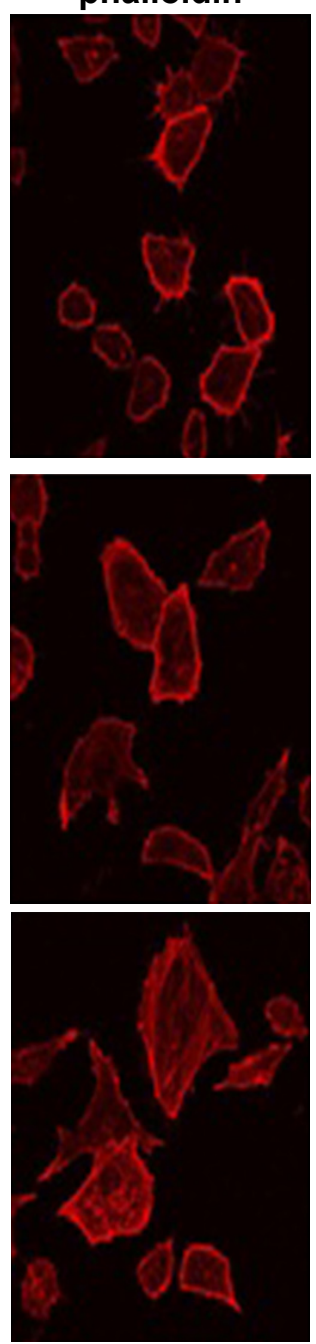

\section{Merged}
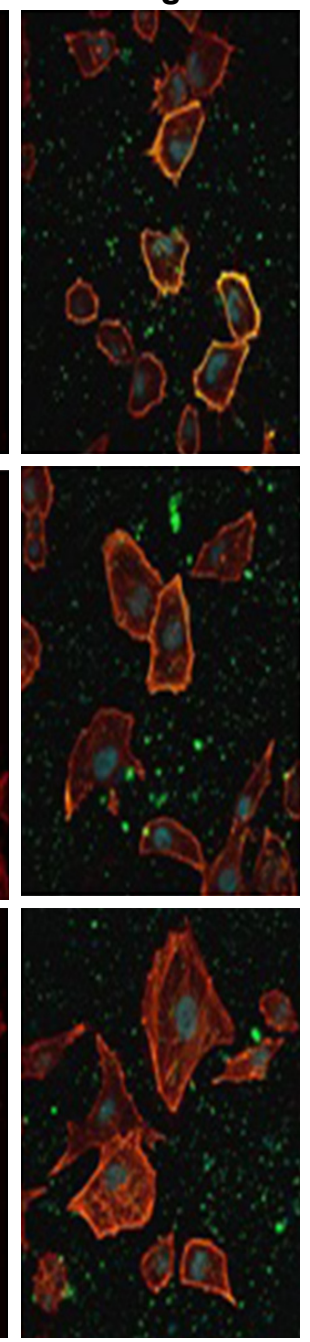

Figure 6 The CLSM images of A549 cells treated with FITC-LCP at various time periods $(\mathbf{A})$ and at various concentrations $(\mathbf{B})$. Magnification $\times 600$. Abbreviations: CLSM, confocal laser scanning microscopy; FITC, fluorescein isothiocyanate; LCP, lipid-coated hollow calcium phosphate.

There was strong colocalization of FITC-LCP and the red dye at early time points, suggesting that LCP was bound to F-actin. With increasing time from 0.5 to $3 \mathrm{~h}$, FITC-LCP was delivered into the cytoplasm, and the amount of uptake gradually increased. Thus, the cellular uptake was time dependent. Figure $6 \mathrm{~B}$ showed that at $1 \mathrm{~h}$ the amount of FITC-LCP uptake also continuously increased when the concentration of FITC-LCP increased from 20 to $50 \mu \mathrm{g} / \mathrm{mL}$. The uptake of FITC-LCP was also dependent on concentration.

The intracellular uptake of FITC-LCP in A549 cells was further investigated by TEM. As shown in Figure 7, FITC-LCP was delivered into A549 cells by endocytosis and distributed to vesicular or cytosolic compartment of cells. It could be obviously observed that the surface of LCP was wrapped by microfilaments. ${ }^{33}$ Microfilaments had an important role on cell adhesion, movement, endocytosis, and so on. Accordingly, the LCP uptake process was associated with the inclusion of microfilaments. The TEM images proved the cellular uptake of FITC-LCP, and this result was consistent with that of the CLSM.

\section{In vivo anti-tumor efficacy}

As shown in Figure 8A, the tumor volumes of PTX/ DOX-LCP and DOX/PTX were much smaller than that of saline group throughout the experimental period. Before the treatment, the mean tumor volumes of saline, DOX/ PTX, and PTX/DOX-LCP groups were 60 $\pm 9,73 \pm 5$, and $65 \pm 6 \mathrm{~mm}^{3}$, respectively. In contrast, the mean tumor volumes of saline, DOX/PTX, and PTX/DOX-LCP groups were $2,540 \pm 12,1,720 \pm 25$, and $1,280 \pm 19 \mathrm{~mm}^{3}$ after treatment. 

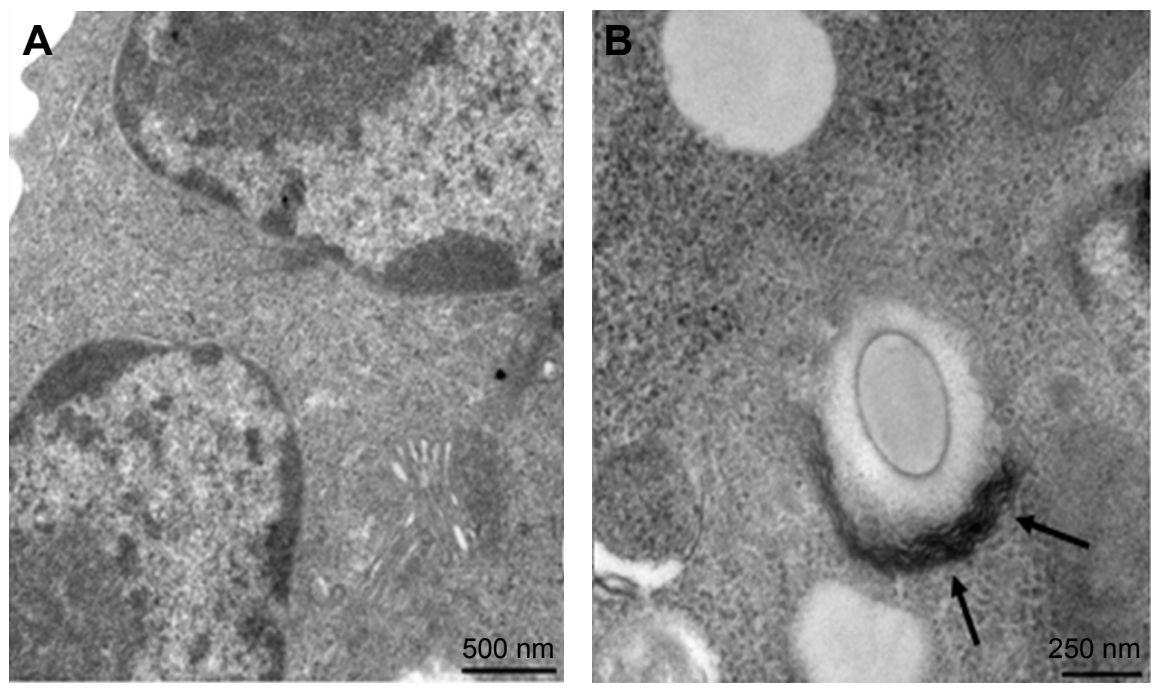

Figure 7 TEM images of FITC-LCP not taken up (A) and intracellular uptake in A549 cells (B). Magnification $\times 20,000$.

Note: Arrows point at microfilaments.

Abbreviations: FITC, fluorescein isothiocyanate; LCP, lipid-coated hollow calcium phosphate; TEM, transmission electron microscopy.

The tumor tissues excised from tumor-bearing nude mice showed different sizes (Figure 8B). The tumor size treated with saline was the largest and those treated with PTX/DOXLCP was the smallest among the three groups. These results indicated that PTX/DOX-LCP significantly inhibited tumor cell proliferation in vivo.

The excised tumor tissues were sectioned to study histopathology. ${ }^{4}$ As shown in Figure 9, the tumor tissue necrotic area in PTX/DOX-LCP group was the largest among the three groups. Nucleus in PTX/DOX-LCP group showed more marked shrinkage and fragmentation. After staining with $\mathrm{H} \& \mathrm{E}$, the viable tumor cells would be stained purple. There were many viable tumor cells observed in groups treated with saline and DOX/PTX. However, viable tumor cells in the tumor tissues of PTX/DOX-LCP group were dramatically reduced. As expected, PTX/DOX-LCP significantly suppressed proliferation of A549 cells compared to DOX/PTX group. In addition, the combined synergistic effect of DOX and PTX was promoted due to favorable cellular uptake and delivery conferred by LCP. Furthermore, LCP improved the absorption of drugs to enhance the treatment concentration of drugs.

\section{Protein expression of $\mathrm{Bax}, \mathrm{Bcl}-2$, and Caspase-3}

The relationship between the expression levels apoptosis factor and apoptosis induction of PTX/DOX-LCP in A549 cells was investigated. The expression levels of Bax, Bcl-2, and Caspase-3 proteins were are in Figure 10. After PTX/ DOX-LCP treatment, Bax and Caspase-3 levels significantly

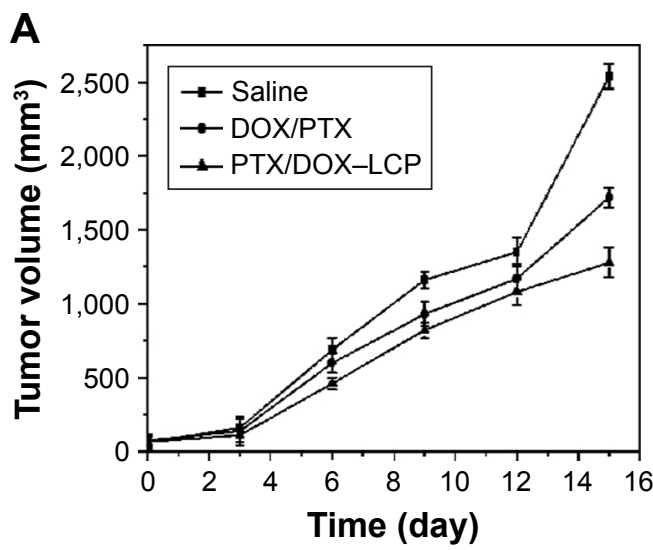

B

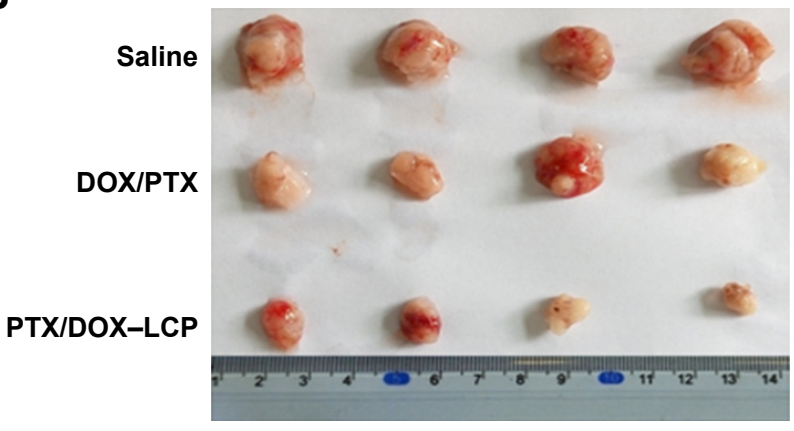

Figure 8 (A) The tumor volume curves of the saline, DOX/PTX, and PTX/DOX-LCP groups. (B) The images of tumor tissues excised from the tumor-bearing nude mice of the saline, DOX/PTX, and PTX/DOX-LCP groups.

Abbreviations: LCP, lipid-coated hollow calcium phosphate; DOX, doxorubicin; PTX, paclitaxel. 

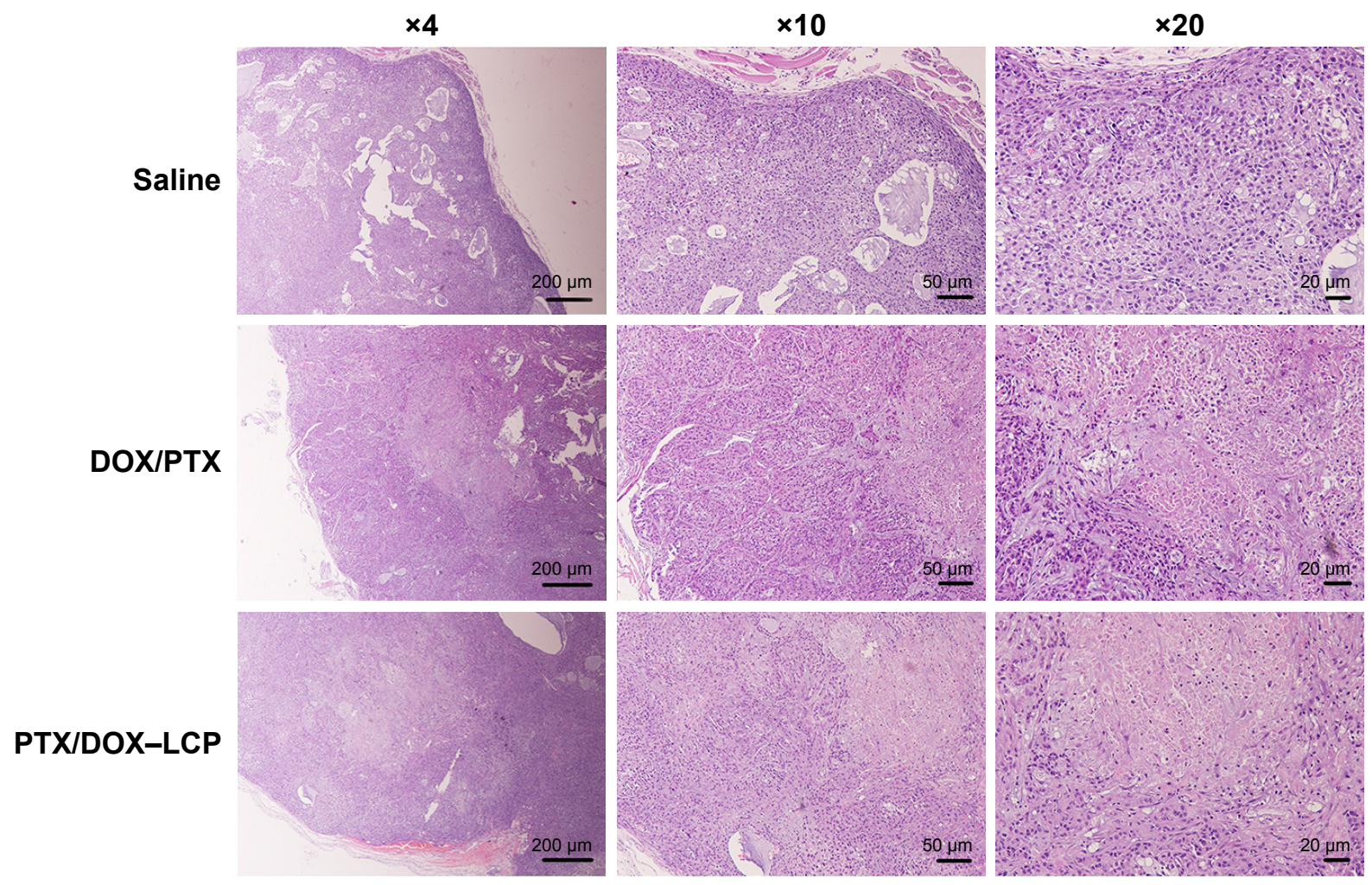

Figure 9 Histological examination of excised tumor tissues of the saline, DOX/PTX, and PTX/DOX-LCP groups under different magnification. Abbreviations: LCP, lipid-coated hollow calcium phosphate; DOX, doxorubicin; PTX, paclitaxel.

increased, while Bcl-2 showed a clear reduction. The increment in Bax protein expression would induce A549 cells apoptosis via the intrinsic pathway. ${ }^{34}$ Moreover, the increase in Caspase-3 protein expression and reduction in $\mathrm{Bcl}-2$ protein expression would also promote cell apoptosis and enhance anti-tumor efficacy. ${ }^{35}$ This experiment showed that

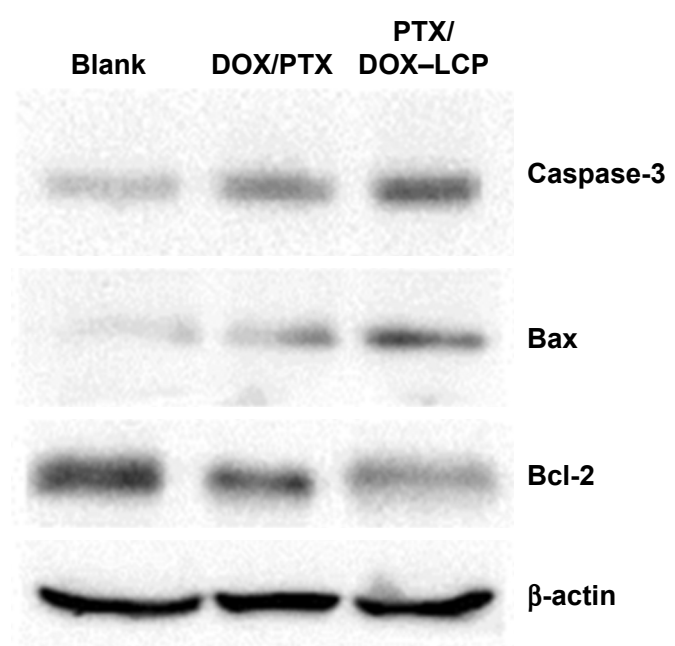

Figure 10 Images of $\mathrm{Bax}, \mathrm{Bcl}-2$, and Caspase-3 protein expression levels of the blank, DOX/PTX, and PTX/DOX-LCP groups.

Abbreviations: LCP, lipid-coated hollow calcium phosphate; DOX, doxorubicin; PTX, paclitaxel. the co-delivery system of PTX and DOX by LCP could regulate the expression of different protein factors to achieve anti-tumor activity.

\section{Conclusion}

According to the evaluation of the HCP coating process, the optimum formulation was obtained for further experiments. The TEM results indicated that monodispersed SPS nanospheres $(257 \mathrm{~nm}), \mathrm{HCP}$ with a hollow structure, and LCP were successfully prepared for co-delivery of PTX and DOX anti-tumor drugs. MTT assay was performed to evaluate the combinational effects of DOX and PTX. When the mass ratio of DOX and PTX was 12:1, the co-delivery system displayed a superb synergistic effect. The loading capacity of PTX and DOX was $3.81 \% \pm 0.13 \%$ and $45.96 \% \pm 0.27 \%$ respectively, which conformed to the synergistic mass ratio of 12:1. The in vitro release experiment showed that LCP produced a sustained drug release to obtain long-lasting therapeutic results and reduced frequency of drug administration to improve therapeutic efficacy. Characterization by PXRD, DSC, and FTIR demonstrated that DOX and PTX were successfully incorporated into LCP in a microcrystalline form and an amorphous form, respectively. CLSM and TEM were conducted to verify that FITC-LCP could be effectively 
taken up by A549 cells. The in vitro cytotoxicity experiment demonstrated that cell inhibition rate of PTX/DOX-LCP was the highest. The apoptosis and in vivo anti-tumor efficacy analyses as well as the analysis of Bax, Bcl-2, and Caspase-3 protein expression levels further proved that PTX/DOX-LCP could suppress tumor proliferation and promote A549 cells apoptosis. In addition, LCP possessed several attractive advantages including good biocompatibility, biodegradability, and nontoxicity. Based on these findings, it has been concluded that LCP appears to be a promising carrier to enhance anti-tumor efficacy.

\section{Acknowledgments}

This study was supported by the National Natural Science Foundation of China (no 81302707), Natural Science Foundation of Liaoning Province (no 2013022052), Liaoning province talent project support programs in colleges and universities (LJQ2015065), Dr Start-up Foundation of Liaoning Province (no 20141195), and by Quanmin Oral Graduate Sci-tech Innovation Foundation, the President Fund of Jinzhou Medical University (no AH2015014).

\section{Disclosure}

The authors report no conflicts of interest in this work.

\section{References}

1. Ma Y, Fan X, Li L. pH-sensitive polymeric micelles formed by doxorubicin conjugated prodrugs for co-delivery of doxorubicin and paclitaxel. Carbohydr Polym. 2016;137:19-29.

2. Duong HH, Yung LY. Synergistic co-delivery of doxorubicin and paclitaxel using multi-functional micelles for cancer treatment. Int $J$ Pharm. 2013;454(1):486-495.

3. Moulder SL, Symmans WF, Booser DJ, et al. Phase I/II study of G3139 (Bcl-2 antisense oligonucleotide) in combination with doxorubicin and docetaxel in breast cancer. Clin Cancer Res. 2008;14(23): 7909-7916.

4. Lv S, Tang Z, Li M, et al. Co-delivery of doxorubicin and paclitaxel by PEG-polypeptide nanovehicle for the treatment of non-small cell lung cancer. Biomaterials. 2014;35:6118-6129.

5. Wang Y, Ma S, Xie Z, Zhang H. A synergistic combination therapy with paclitaxel and doxorubicin loaded micellar nanoparticles. Colloids Surf B Biointerfaces. 2014;116:41-48.

6. Chen Y, Zhang W, Huang Y, Gao F, Sha X, Fang X. Pluronic-based functional polymeric mixed micelles for co-delivery of doxorubicin and paclitaxel to multidrug resistant tumor. Int J Pharm. 2015;488:44-58.

7. Feng T, Tian H, Xu C, et al. Synergistic co-delivery of doxorubicin and paclitaxel by porous PLGA microspheres for pulmonary inhalation treatment. Eur J Pharm Biopharm. 2014;88:1086-1093.

8. Wang H, Zhao Y, Wu Y, et al. Enhanced anti-tumor efficacy by codelivery of doxorubicin and paclitaxel with amphiphilic methoxy PEGPLGA copolymer nanoparticles. Biomaterials. 2011;32:8281-8290.

9. Ye F, Guo H, Zhang H, He X. Polymeric micelle-templated synthesis of hydroxyapatite hollow nanoparticles for a drug delivery system. Acta Biomater. 2010;6:2212-2218.

10. Li ZZ, Wen LX, Shao L, Chen JF. Fabrication of porous hollow silica nanoparticles and their applications in drug release control. J Control Release. 2004;98(2):245-254.
11. Li X, Du P, Liu P. Novel biocompatible pH-stimuli responsive superparamagnetic hybrid hollow microspheres as tumor-specific drug delivery system. Colloids Surf B Biointerfaces. 2014;122:99-106.

12. Meng DL, Shang L, Feng XH, Huang XF, Che X. Xanthoceraside hollow gold nanoparticles, green pharmaceutics preparation for poorly watersoluble natural anti-AD medicine. Int J Pharm. 2016;506:184-190.

13. Li G, Yu N, Gao Y, Tao Q, Liu X. Polymeric hollow spheres assembled from ALG-g-PNIPAM and beta-cyclodextrin for controlled drug release. Int J Biol Macromol. 2016;82:381-386.

14. Lu BQ, Zhu YJ, Chen F, Qi C, Zhao XY, Zhao J. Core-shell hollow microspheres of magnetic iron oxide@amorphous calcium phosphate: synthesis using adenosine $5^{\prime}$-triphosphate and application in pH-responsive drug delivery. Chem Asian J. 2014;9:2908-2914.

15. Zhang J, Jin Y, Li C, et al. Creation of three-dimensionally ordered macroporous $\mathrm{Au} / \mathrm{CeO} 2$ catalysts with controlled pore sizes and their enhanced catalytic performance for formaldehyde oxidation. Appl Catal B. 2009;91:11-20.

16. Cai W, Wang W, Lu L, Chen T. Coating sulfonated polystyrene microspheres with highly dense gold nanoparticle shell for SERS application. Colloid Polym Sci. 2013;291:2023-2029.

17. Li WM, Chen SY, Liu DM. In situ doxorubicin-CaP shell formation on amphiphilic gelatin-iron oxide core as a multifunctional drug delivery system with improved cytocompatibility, $\mathrm{pH}-$ responsive drug release and MR imaging. Acta Biomater. 2013;9:5360-5368.

18. Li WM, Su CW, Chen YW, Chen SY. In situ DOX-calcium phosphate mineralized CPT-amphiphilic gelatin nanoparticle for intracellular controlled sequential release of multiple drugs. Acta Biomater. 2015; 15:191-199.

19. Meng H, Wang M, Liu H, et al. Use of a lipid-coated mesoporous silica nanoparticle platform for synergistic gemcitabine and paclitaxel delivery to human pancreatic cancer in mice. ACS Nano. 2015;9: 3540-3557.

20. She X, Chen L, Velleman L, et al. Fabrication of high specificity hollow mesoporous silica nanoparticles assisted by Eudragit for targeted drug delivery. J Colloid Interface Sci. 2015;445:151-160.

21. Al-Abd AM, Hong KY, Song SC, Kuh HJ. Pharmacokinetics of doxorubicin after intratumoral injection using a thermosensitive hydrogel in tumor-bearing mice. J Control Release. 2010;142:101-107.

22. Ji X, Gao Y, Chen L, Zhang Z, Deng Y, Li Y. Nanohybrid systems of non-ionic surfactant inserting liposomes loading paclitaxel for reversal of multidrug resistance. Int J Pharm. 2012;422:390-397.

23. Chittasupho C, Lirdprapamongkol K, Kewsuwan P, Sarisuta N. Targeted delivery of doxorubicin to A549 lung cancer cells by CXCR4 antagonist conjugated PLGA nanoparticles. Eur J Pharma Biopharm. 2014;88:529-538.

24. Kesisoglou F, Panmai S, Wu Y. Nanosizing - oral formulation development and biopharmaceutical evaluation. Adv Drug Deliv Rev. 2007; 59:631-644

25. Li Q, Lv S, Tang Z, et al. A co-delivery system based on paclitaxel grafted mPEG-b-PLG loaded with doxorubicin: preparation, in vitro and in vivo evaluation. Int J Pharm. 2014;471:412-420.

26. Ahern RJ, Hanrahan JP, Tobin JM, Ryan KB, Crean AM. Comparison of fenofibrate-mesoporous silica drug-loading processes for enhanced drug delivery. Eur J Pharm Sci. 2013;50:400-409.

27. Jiang H, Wang T, Wang L, et al. Development of an amorphous mesoporous $\mathrm{TiO}_{2}$ nanosphere as a novel carrier for poorly water-soluble drugs: effect of different crystal forms of $\mathrm{TiO} 2$ carriers on drug loading and release behaviors. Microporous Mesoporous Mater. 2012;153:124-130.

28. Zhao P, Jiang H, Jiang T, et al. Inclusion of celecoxib into fibrous ordered mesoporous carbon for enhanced oral bioavailability and reduced gastric irritancy. Eur J Pharm Sci. 2012;45:639-647.

29. Zhang Y, Wang H, Gao C, Li X, Li L. Highly ordered mesoporous carbon nanomatrix as a new approach to improve the oral absorption of the waterinsoluble drug, simvastatin. Eur J Pharm Sci. 2013;49:864-872.

30. Xie Y, Liu Y, Wang Y, Wang S, Jiang T. Chitosan matrix with three dimensionally ordered macroporous structure for nimodipine release. Carbohydr Polym. 2012;90:1648-1655. 
31. Hu Y, Zhi Z, Wang T, Jiang T, Wang S. Incorporation of indomethacin nanoparticles into 3-D ordered macroporous silica for enhanced dissolution and reduced gastric irritancy. Eur J Pharm Biopharm. 2011;79: 544-551.

32. Zhao Z, Wu C, Zhao Y, Hao Y, Liu Y, Zhao W. Development of an oral push-pull osmotic pump of fenofibrate-loaded mesoporous silica nanoparticles. Int J Nanomed. 2015;10:1691-1701.

33. Monti DM, Guarnieri D, Napolitano G, et al. Biocompatibility, uptake and endocytosis pathways of polystyrene nanoparticles in primary human renal epithelial cells. J Biotechnol. 2015;193:3-10.
34. Morales-Cano D, Calvino E, Rubio V, et al. Apoptosis induced by paclitaxel via Bcl-2, Bax and caspases 3 and 9 activation in NB4 human leukaemia cells is not modulated by ERK inhibition. Exp Toxicol Pathol. 2013;65:1101-1108.

35. Zeng CC, Jiang GB, Lai SH, et al. Synthesis, characterization and anticancer activity studies of ruthenium(II) polypyridyl complexes on A549 cells. J Photochem Photobiol B. 2016;161:295-303.

\section{Publish your work in this journal}

The International Journal of Nanomedicine is an international, peerreviewed journal focusing on the application of nanotechnology in diagnostics, therapeutics, and drug delivery systems throughout the biomedical field. This journal is indexed on PubMed Central, MedLine, CAS, SciSearch ${ }^{\circledR}$, Current Contents ${ }^{\circledR} /$ Clinical Medicine,
Journal Citation Reports/Science Edition, EMBase, Scopus and the Elsevier Bibliographic databases. The manuscript management system is completely online and includes a very quick and fair peer-review system, which is all easy to use. Visit http://www.dovepress.com/ testimonials.php to read real quotes from published authors. 